BMJ Open Sport \& Exercise Medicine

\title{
Incidence and prediction of ankle injury risk: a prospective cohort study on 91 contemporary preprofessional dancers
}

\author{
Adinda K E Mailuhu, ${ }^{1}$ Rogier M van Rijn (D) ,2,3 Janine H Stubbe, ${ }^{1,2,3,4}$ \\ Sita M A Bierma-Zeinstra, ${ }^{1}$ Marienke van Middelkoop ${ }^{1}$
}

To cite: Mailuhu AKE, van Rijn RM, Stubbe JH, et al. Incidence and prediction of ankle injury risk: a prospective cohort study on 91 contemporary preprofessional dancers. BMJ Open Sport \& Exercise Medicine 2021;7:e01060. doi:10.1136/ bmjsem-2021-001060

Accepted 28 May 2021
Check for updates

(c) Author(s) (or their employer(s)) 2021. Re-use permitted under CC BY-NC. No commercial re-use. See rights and permissions. Published by BMJ.

'Department of General Practice, Erasmus MC University Medical Center, Rotterdam, the Netherlands

${ }^{2}$ Codarts Rotterdam, University of the Arts, Rotterdam, the Netherlands

${ }^{3}$ PErforming Artist and Athlete Research Lab (PEARL), Rotterdam, the Netherlands ${ }^{4}$ Rotterdam Arts and Sciences Lab (RASL), Rotterdam, the Netherlands

Correspondence to Dr Rogier M van Rijn; rmvanrijn@codarts.nl

\section{ABSTRACT}

Objectives This study examines the incidence of ankle injuries and identifies ankle injury risk among contemporary preprofessional dancers.

Methods A total of 91 first-year contemporary preprofessional dancers were prospectively followed during one academic year. Self-reported ankle injuries, assessed with the Oslo Sports Trauma Research Centre questionnaire, were categorised as all complaint ankle injuries, substantial ankle injuries or time-loss ankle injuries. In addition, ankle injuries leading to medical attention were included. Regression analyses were used to determine the association between potential risk factors (dancer characteristics, history of ankle injury in the previous year, ankle range of motion and dorsiflexion) and ankle injuries.

Results The 1-year ankle injury incidence proportion was $18.7 \%(n=17), 8.8 \%(n=8), 15.4 \%(n=14)$ and $7.7 \%$ $(n=7)$, respectively, for all complaint ankle injuries, ankle injuries requiring medical attention, time-loss injuries and substantial injuries. Being male $(\mathrm{OR}=0.27 ; 95 \% \mathrm{Cl} 0.09$ to 0.75 ) and being a student of the Bachelors in Dance and Education $(\mathrm{OR}=0.27 ; 95 \% \mathrm{Cl} 0.08$ to 0.97$)$ were univariately associated with a lower risk of an ankle injury. Conclusion Almost 20\% of first-year preprofessional dancers reported an ankle injury, with more than $80 \%$ of the dancers reporting that their injury leads to dance time loss. Males and students of the bachelors in dance and education were at lower risk of ankle injuries. As ankle injuries are common among dancers, studies with larger sample sizes, a more heterogeneous population (eg, different dance styles) and longer follow-up periods are necessary to evaluate the impact of ankle injuries in further detail.

\section{INTRODUCTION}

Preprofessional dancers must endure highly intensive academic training from a relatively young age with many training hours to become a professional dancer. ${ }^{1}$ These demands can cause health hazards ${ }^{2}$ and may lead to discomfort, medical treatment, absence from dance activities, study delay and even dropping out of college.

Preprofessional dancers have a high prevalence of overuse injuries, ranging from $56 \%$

\section{Key messages}

What is already known?

- Pre-professional dancers have a high prevalence of injuries, with the ankle being one of the most frequently injured locations

- Until now, no studies investigated factors associated with a higher ankle injury risk among preprofessional dancers.

What are the new findings?

- Preprofessional dancers are at high risk for ankle injuries, with the majority of these injuries leading to dance time loss and thereore injury prevention programmes in dance universities should focus on the prevention of ankle injuries.

- Dance universities must especially create awareness in women and students of the bachelors in dance as they seem to be more prone to ankle injuries.

- Ankle injury incidence proportion varies greatly depending on the injury definition. To gain insight into the number of dance injuries in different target populations, we recommend using standardised injury definitions.

to $72 \%$, with the ankle being one of the most frequently injured locations with a prevalence of $17 \%-33 \% .^{2-7}$ In preprofessional ballet dancers, evidence has indicated that ankle injuries resulted in an absence from ballet for more than a month. ${ }^{8}$ After sustaining an ankle injury, up to $76 \%$ of modern and ballet dance majors developed chronic ankle instability, which can affect the performance of dance ${ }^{9}$ and cause dancers to retire from professional dancing. ${ }^{10}$ Considering the high prevalence and impact of ankle injuries among dancers, it is important to identify the risk factors for sustaining an ankle injury to develop preventive measures. Previous studies have determined risk factors for general dancerelated injuries ${ }^{11}$ or for injuries in specific body regions (eg, lower extremity). ${ }^{12}$ To our knowledge, no study has identified factors specifically for ankle injuries among preprofessional dancers. 
A first step towards the development of preventive measures for injuries is the evaluation of the injury incidence. ${ }^{13}$ To date, different ankle injury definitions (eg, injury leading to time-loss or medical attention) are used to describe the incidence of ankle injuries among dancers. ${ }^{81415}$ Clarsen et al proposed an injury surveillance method that also takes overuse into account. ${ }^{16}$ Presenting the incidence of ankle injuries according to this method will capture a more comprehensive picture of the burden of ankle injuries in preprofessional dancers and may aid early detection of the problem. This study aimed to examine the incidence of ankle injuries during the academic training of preprofessional dancers, using different injury definitions (ie, all complaints, medical attention, time-loss and substantial ankle injuries). The second aim was to identify factors associated with a higher ankle injury risk among first-year contemporary preprofessional dancers.

\section{METHODS AND MATERIALS Subjects}

This prospective cohort study was performed among firstyear contemporary preprofessional dancers (full time) at the Codarts University of the Arts, Rotterdam, the Netherlands. Preprofessional dancers were included from the bachelors in dance (BD) and bachelors in dance and education (BDE) from the academic years 2017-2018 and 2018-2019 (September-June). All dancers provided written informed consent before participation.

\section{Baseline measurements}

At the start of the academic year, all BD and BDE dancers completed an intake questionnaire including questions on age (years), sex, weight $(\mathrm{kg})$, height $(\mathrm{cm})$ and history of a long-lasting ankle injury during the previous year (ie, any physical complaint resulting in a full time-loss of dance activity (participation in class, rehearsal, performance, practice, etc) for 1 week or more beyond the day of onset). Throughout one academic year, dance exposure in hours (ie, time exposure) was retrieved, for both $\mathrm{BD}$ and $\mathrm{BDE}$, respectively, from the students' training schedule. $^{17}$

In addition, all preprofessional dancers underwent a physical screening, including ankle range of motion (ROM) and dorsal flexion of both ankles. ROM was assessed by the in-house physiotherapist, specialised in dance medicine, and was categorised as follows: normal, hypomobile or hypermobile. The classification was based on the experience of the physiotherapist.

To determine both ankles' dorsal flexion, all dancers performed the weight-bearing lunge test. ${ }^{18}$ For this test, the dancers were asked to place their foot so that an imaginary line drawn through the heel and big toe would be aligned with a tape measure on the floor. Furthermore, a vertical line was drawn on the wall in line with the tape measure. Dancers were instructed to lunge forward with their knee touching the wall while their foot remained flat on the ground. Subsequently, due to this position, the ankle was placed in maximal dorsiflexion, and the distance from the wall to the great toe was measured in centimetres (each centimetre corresponds to approximate ankle dorsiflexion of $\left.3.6^{\circ}\right) .^{18}$

\section{Follow-up measurements}

Both cohorts (2017-2018 and 2018-2019) were followed for one academic year (September-June). During the academic year, all preprofessional dancers were asked to complete monthly questionnaires using the performing artist and athlete health monitor. This web-based system monitors the physical and mental health of performing artists and athletes. ${ }^{2} 1920$ If the monthly questionnaire was not completed, a reminder e-mail was sent out to the dancers. Data of follow-up measurements were included in the current study if the dancer completed at least $30 \%$ of the questionnaires during one academic year. ${ }^{2}$

\section{Monitoring ankle injuries during the academic year}

Three different methods were used to monitor ankle injuries:

1. The monthly questionnaire included the Oslo Sports Trauma Research Centre (OSTRC) Questionnaire on Health Problems. ${ }^{16}$ This questionnaire contains four key questions on the consequences of an injury on participation/performance and to what extent the respondent experienced symptoms. Each question ranged between 0 (no problem) to 25 (cannot participate at all or severe symptoms) on a 4-point or 5-point scale. The scores of the four questions were summed to calculate a severity score from 0 (no health problem) to 100 (cannot participate at all because of severe health problems). ${ }^{16}$ If the severity score was 0 , the questionnaire was classed as complete. If the score was greater than 0 , the student was asked what type of health problem they referred to: physical injury, mental health problem or other problem (eg, illnesses such as the influenza, fever, accidents or operations). If the preprofessional dancers indicated a physical injury, the dancer was automatically directed to an injury registration form based on an international consensus statement on injury surveillance methodology for football to collect further details (eg, location, history, acute or gradual onset).$^{21}$ For this study, only ankle-related health problems were included.

2. All preprofessional dancers had access to the health team affiliated with the university, which included three physiotherapists. All medical attention ankle injuries were reported on a standard injury report form by the physiotherapists. The report form included details as to the type of injury and a diagnosis.

3. Preprofessional dancers who reported an ankle injury in the monthly questionnaires were asked to report the number of days they could not fully participate in dance training or performances due to their ankle injury over the previous 4 weeks. 


\section{Ankle injury definitions}

Ankle injuries were categorised by using the following four definitions:

1. All complaints ankle injury: any physical complaint located at the ankle resulting in a severity score higher than zero on the OSTRC questionnaire, irrespective of the need for medical attention or time-loss from dance activities.

2. Substantial ankle injury: an ankle injury leading to moderate or severe reductions in training volume, sports performance or a complete inability to participate in dance (score $\geq 13$ on question 2 or 3 of the OSTRC questionnaire). ${ }^{16}$

3. Ankle injury leading to dance time-loss: an ankle injury resulting in the inability to complete a rehearsal, performance or class (or a subsequent rehearsal, performance or class) one or more days beyond the day of onset. $^{1721}$

4. Ankle injury leading to medical attention: an ankle injury resulting in a dancer seeking care from the medical team (ie, physiotherapist) within the university. ${ }^{1721}$

Injuries reported in two or more consecutive months on the same ankle were considered the same ankle injury (ie, ongoing injury). Injuries reported across nonconsecutive months, or injuries on the contralateral ankle during follow-up, were considered unique ankle injuries.

\section{Statistical analysis}

All analyses were performed with the SPSS V.25.0. (IBM) with the significance level set to 0.05 . Descriptive statistics were used to describe the baseline characteristics of the preprofessional dancers (ie, age, gender, body mass index (BMI), dance exposure) and the outcome of the physical tests at the start of the academic training (ie, ankle ROM and ankle dorsal flexion) using means and SD for continuous data, and numbers and percentages (\%) for categorical data.

The incidence proportion (IP) of ankle injuries (ie, all, substantial, time-loss and medical attention) was calculated by dividing the number of dancers that reported at least an all complaints ankle injury/substantial ankle injury/time-loss ankle injury/medical attention ankle injury during the academic year divided by the total number of respondents. ${ }^{22}$ The injury incidence rate was calculated as the number of injuries (ie, all, substantial, time-loss and medical attention) per 1000 hours spent on dance activities. ${ }^{21}$ The corresponding $95 \%$ CIs were obtained using the following formula: (\#injuries/exposure $\pm 1.96 \mathrm{SE}) * 1000 .^{22}$

To identify factors associated with the occurrence of ankle injuries among the preprofessional dancers, both univariate and multivariate regression models were performed on leg-level, using generalised estimating equations. These models take into account the association between two legs within one person. Potential factors included age (years), sex (male), BMI $\left(\mathrm{kg} / \mathrm{m}^{2}\right)$, educational programme (BDE), history of a long-lasting ankle injury during the previous year, ankle ROM and
First-year contemporary pre-professional dancers

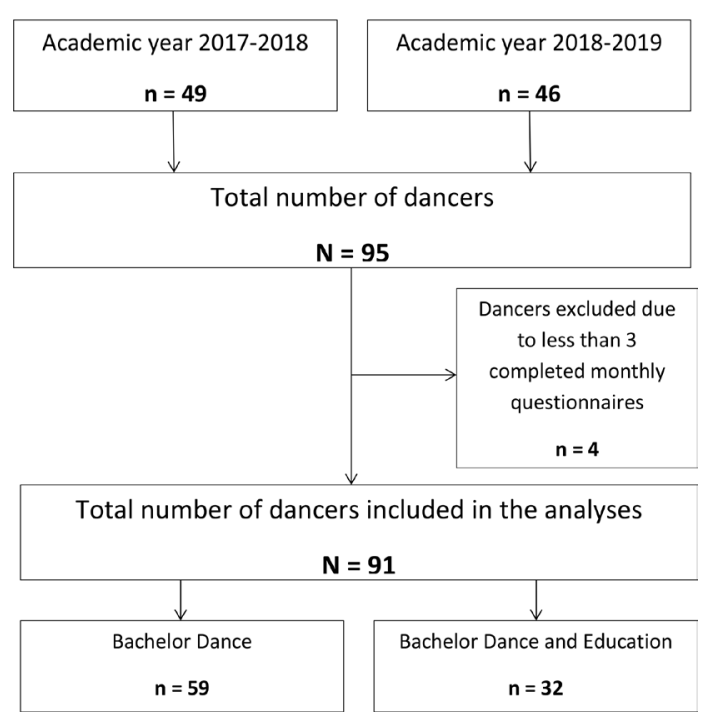

Figure 1 Flow chart of the preprofessional dancers included in the current study.

ankle dorsal flexion. The independent variable, ankle ROM, was dichotomised into normal and abnormal for the regression analyses. A hypomobile and hypermobile ankle was defined as an abnormal ankle ROM and a normal ankle ROM used as the reference category. Variables from the univariate analyses with a $\mathrm{p}<0.20$ were included in the multivariate analysis. In addition, to determine the number of factors to be included in the multivariate analysis, we accounted for the one in ten rule. $^{2324}$ The regression analyses' results were expressed in ORs with their corresponding $95 \%$ CIs.

\section{Patient and public involvement}

Patients or the public were not involved in this research's design, conduct, reporting or dissemination plans.

\section{RESULTS}

\section{Response and baseline characteristics}

During the academic years of 2017-2018 and 2018-2019, 95 first-year contemporary preprofessional dancers were invited for the medical screening and were asked to fill in the questionnaires each month. All dancers gave consent to participate. $72.5 \%$ of the dancers completed all 9 monthly questionnaires. Four dancers completed less than $30 \%$ of the questionnaires. Therefore, 91 dancers (59 BD, $32 \mathrm{BDE}$ ) were included in the analyses, resulting in a response rate of $95.8 \%$ (figure 1). Baseline characteristics of these 91 pre-professional dancers are shown in table 1 .

\section{Incidence of ankle injuries}

Across the two academic years, 17 preprofessional dancers reported a total of 33 ankle injuries. Of these, 23 were unique cases. The remaining 10 ankle injuries were ongoing injuries. These injuries were recorded in at least two consecutive questionnaires and therefore were not 
Table 1 Characteristics of dance students at baseline

\begin{tabular}{|c|c|c|c|}
\hline & $\begin{array}{l}\text { Total population } \\
\mathrm{N}=91\end{array}$ & $\begin{array}{l}\text { Bachelors dance } \\
\mathrm{N}=59\end{array}$ & $\begin{array}{l}\text { Bachelors dance education } \\
\mathrm{N}=32\end{array}$ \\
\hline Age (years), mean $\pm S D$ & $19.2 \pm 1.5$ & $18.9 \pm 1.0$ & $19.8 \pm 2.1$ \\
\hline Sex (male) & $27(29.7 \%)$ & $27(45.8 \%)$ & $0(0.0 \%)$ \\
\hline BMI $\left(\mathrm{kg} / \mathrm{m}^{2}\right)$, mean $\pm \mathrm{SD}$ & $21.2 \pm 2.0$ & $20.9 \pm 1.6^{\star}$ & $21.8 \pm 2.4$ \\
\hline $\begin{array}{l}\text { Dance exposure (total hours per academic } \\
\text { year/student) }\end{array}$ & $1055.5 \pm 276.2$ & 1257.8 & 682.5 \\
\hline $\begin{array}{l}\text { History of a long-lasting ankle injury in the } \\
\text { past year }\end{array}$ & $2(2.2 \%)$ & $1(1.7 \%)$ & $1(3.1 \%)$ \\
\hline \multicolumn{4}{|l|}{ Physical tests at the start of the training } \\
\hline \multicolumn{4}{|l|}{ Ankle range of motion } \\
\hline \multicolumn{4}{|l|}{ Left } \\
\hline Hypomobile & $6(6.6 \%)$ & $5(8.5 \%)$ & $1(3.1 \%)$ \\
\hline Normal & $77(84.6 \%)$ & $46(78.0 \%)$ & $31(96.9 \%)$ \\
\hline Hypermobile & $8(8.8 \%)$ & $8(13.6 \%)$ & $0(0.0 \%)$ \\
\hline \multicolumn{4}{|l|}{ Right } \\
\hline Hypomobile & $5(5.5 \%)$ & $5(8.5 \%)$ & 0 \\
\hline Normal & $77(84.6 \%)$ & $45(76.3 \%)$ & $32(100.0 \%)$ \\
\hline Hypermobile & $9(9.9 \%)$ & $9(15.3 \%)$ & $0(0.0 \%)$ \\
\hline \multicolumn{4}{|l|}{$\begin{array}{l}\text { Ankle dorsal flexion (wall-to-toe distance in } \\
\mathrm{cm} \text { ) (SD) }\end{array}$} \\
\hline Left & $14.4 \pm 2.6 \ddagger$ & $14.5 \pm 2.7 \S$ & $14.1 \pm 2.4 \rrbracket$ \\
\hline Right & $14.8 \pm 2.7 \ddagger$ & $14.7 \pm 2.6 \S$ & $14.9 \pm 2.99$ \\
\hline
\end{tabular}

Presented in $\mathrm{n}(\%)$, unless otherwise stated.

${ }^{*} n=4$ missing.

†Measured with the weight-bearing lunge test.

$\ddagger \mathrm{n}=4$ missing.

$\S n=3$ missing.

In=1 missing.

BMI, body mass index.

categorised as unique injuries. The ankle injury IP for one academic year was $18.7 \%(\mathrm{n}=17), 8.8 \% \quad(\mathrm{n}=8), 15.4 \%$ $(\mathrm{n}=14)$ and $7.7 \%(\mathrm{n}=7)$ for all complaints ankle injuries, medical attention ankle injuries, time-loss ankle injuries and substantial ankle injuries, respectively.

The 59 BD students spent on average 1257.75 hours per academic year on dance activities, resulting in a total exposure of 74207.25 hours during the year. On average, the $32 \mathrm{BDE}$ students spent 682.50 hours per academic year on dance activities, resulting in a total exposure of 21840 hours across the academic year. The total exposure for all dance students was 96047.25 hours. The total time equates to incidence rates (ankles injuries/1000 dance exposure hours) of 0.24 (95\% CI 0.14 to 0.34 ), 0.08 (95\% CI 0.03 to 0.14 ), 0.10 (95\% CI 0.04 to 0.17 ) and 0.17 (95\% CI 0.08 to 0.25 ) for all complaint ankle injuries, medical attention ankle injuries, time-loss ankle injuries and substantial ankle injuries, respectively.

\section{Who is at risk for an ankle injury?}

The univariate analyses indicated a negative association for males $(\mathrm{OR}=0.27 ; 95 \% \mathrm{CI} 0.09$ to 0.75$)$ and dancers from the $\mathrm{BDE}(\mathrm{OR}=0.27 ; 95 \% \mathrm{CI} 0.08$ to 0.97$)$ with the occurrence of an ankle injury during the academic year (table 2). These associations were no longer significant in the multivariate analysis; males $(\mathrm{OR}=0.36 ; 95 \% \mathrm{CI} 0.12$ to $1.12 ; \mathrm{p}=0.08)$ and $\mathrm{BDE}(\mathrm{OR}=0.48 ; 95 \% \mathrm{CI} 0.12$ to 1.89 ; $\mathrm{p}=0.29$ ).

\section{DISCUSSION}

In the current study, 91 first-year contemporary preprofessional dancers from the $\mathrm{BD}$ and $\mathrm{BDE}$ were included. Almost $20 \%$ of the dancers $(n=17)$ reported an ankle injury, with a total of 23 unique ankle injuries throughout the academic year. Males and dancers on the BDE had a lower ankle injury risk during the academic year.

Several studies have evaluated musculoskeletal injuries among preprofessional and professional dancers. ${ }^{2-4} 812$ 25-28 Some of these studies reported the incidence of ankle injuries which ranged between $17 \%$ and 53\%. ${ }^{2726}$ Compared with these studies, our study's IP is relatively low, which may be partly explained by the difference in follow-up time. Several previous studies had 
Table 2 Univariate analyses of potential risk factors for the occurrence of ankle injuries among dance students (total $\mathrm{n}=91$ with number of legs $=182$ )

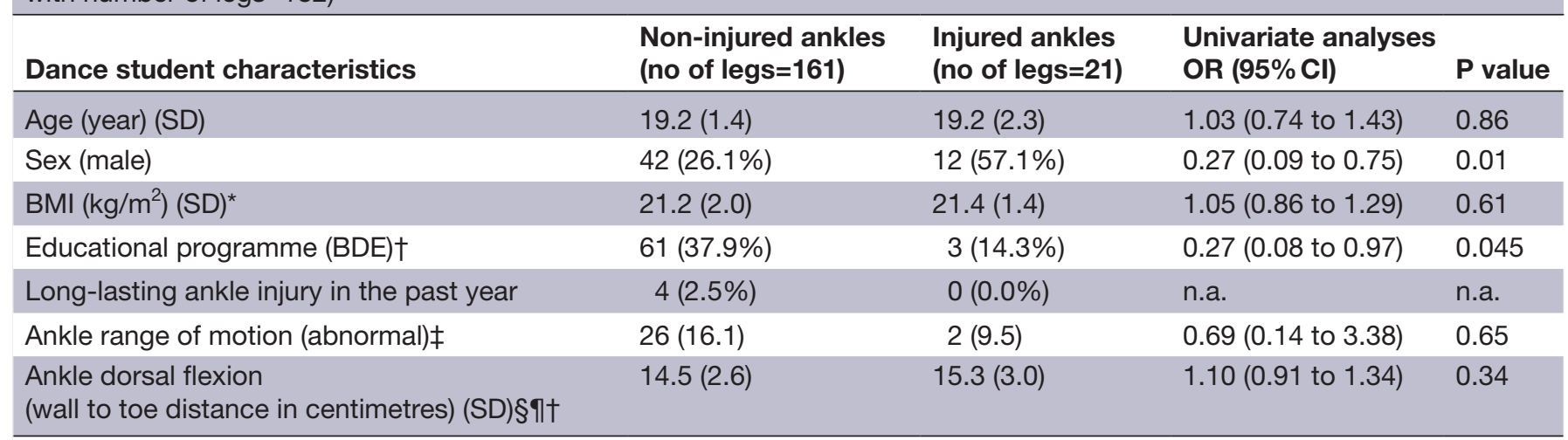

Presented in $\mathrm{n}(\%)$, unless otherwise stated.

${ }^{*}$ Missing data from four dance students (eight legs).

†Reference category is the educational programme bachelors in dance.

†Range of motion dichotomised into normal and abnormal (hypermobile and hypomobile range of motion), with a normal range of motion as the reference category.

§Measured with the weight-bearing lunge test.

१Missing data from 4 dance students (8 legs).

BDE, bachelors in dance education; BMI, body mass index; ; n.a., not available.

a follow-up time of 5-10 years, ${ }^{426} 27$ while we included two cohorts with a follow-up period of one academic year. As such, the incidence of injury expressed in hours of exposure seems a better measure to compare results. While some studies presented injury rates per 1000 dance exposure hours, ${ }^{235}$ none specifically presented these rates for ankle injuries. We calculated the incidence rate of ankle injuries $(n=23)$ per 1000 dance exposure hours based on the total group exposure and found an incidence rate of 0.24 (95\% CI 0.14 to 0.34 ). Compared with general injury rates per 1000 dance exposure hours within the literature $^{235}$ (range between 1.2 and 1.9 injuries per 1000 dance exposure hours), our incidence rate was lower than the rates reported. This is expected because we focused only on ankle injuries and did not account for all dance injuries in the analyses.

Our results showed that the ankle injury IP varies greatly depending on the injury definition, ranging from $7.7 \%$ to $18.7 \%$. This is consistent with previous research applying multiple injury definitions to all dance-related injuries. ${ }^{14}$ Of note, there were almost twice as many time-loss injuries than medical attention injuries. The under-representation of medical attention injuries in a population of preprofessional dancers might be due to the fear of not being allowed to participate in classes, rehearsals or performances. ${ }^{14172529}$ Conversely, confidential self-reporting allowed dancers to report injuries they otherwise might not have reported to the health team. ${ }^{30}$ As with preprofessional dancers, similar beliefs of fear and avoidance also play a role in injury reporting among professional dancers. Vassallo et al investigated injury fear and injury reporting behaviours in 146 professional dancers in Australia. They found that more than $50 \%$ of dancers fear the consequences of sustaining a dance-related injury and that this stigma had delayed reporting the injury or seeking medical care. ${ }^{31}$

To gain insight into the number of dance injuries in different target populations, we recommend using standardised injury definitions. In addition, this may also contribute to facilitating the synthesis of evidence in future systematic reviews and meta-analyses.

Due to the prevalence of sustaining a musculoskeletal injury among preprofessional dancers, it is important to identify who sustains these injuries. ${ }^{13}$ We found two significant independent variables associated with injury prevalence in our univariate analyses (sex and educational programme), but these variables were no longer significant in our multivariate analysis.

The relatively small population might explain this, as the follow-up period was only short term (12 months). In this time, we could only identify a small number of reported ankle injuries, and thus, fewer variables were entered into our regression analysis. ${ }^{2324}$ The selection of these variables was based on the existing literature. For example, it has been reported that bodyweight seems to be related to ankle injuries and that limited dorsiflexion has been observed with a higher risk of lower extremity injuries across athletes and dancers. ${ }^{8} 123233$ However, none of these factors was significantly associated with ankle injuries in our population. It remains difficult to compare our findings with the existing literature. Most previous studies investigating dance populations evaluated risk factors for injuries in general or injuries to a specific part of the body, for example, lower extremity. Still, they did not evaluate factors associated with ankle injuries specifically. ${ }^{1234}$ Studies that describe injury epidemiology and injury risk of general dance-related injuries in a population of preprofessionals show inconclusive findings. In 
contrast to our results, a prospective cohort study among preprofessional reported a significantly higher number of injuries in male dancers compared with the female dancers. ${ }^{7}$ In addition, several other prospective cohort studies did not show an association between sex, ${ }^{3} 1235$ educational programme ${ }^{1232}$ and injury risk. Therefore, the role of sex on the incidence of injuries remains largely unclear.

Although we found a rather low incidence of ankle injuries, we believe that the impact of ankle injuries should not be underestimated. The ankle is the most common type of injury among dancers and is already reported by up to $17 \%$ of dance students in the first year of their academic training. ${ }^{325}$ Furthermore, it has been reported that out of all musculoskeletal injuries or diseases, ankle injuries among preprofessional dancers resulted in the longest absence from dance. In professional dancers, it was one of the main reasons for retirement. ${ }^{810}$ After a dancer sustains an ankle sprain, more than 50\% reported chronic ankle instability, which can significantly impact dance performance. ${ }^{9}$ Therefore, first-year preprofessional dancers are a potentially suitable target group to prevent ankle injuries. The first step towards prevention is the recognition of who sustains ankle injuries. When the factors for ankle injuries can be determined in firstyear pre-professional dancers, the dancers at risk for sustaining an ankle injury during their training can be recognised at an early stage.

\section{Strengths and limitations}

To our knowledge, this is the first study that focuses specifically on ankle injuries in contemporary preprofessional dancers in terms of incidence and factors associated with ankle injuries. Due to a high response rate during follow-up $(95.8 \%$ completed three or more monthly questionnaires, $72.5 \%$ completed all 9 monthly questionnaires), we have likely included all ankle injuries that occurred during the academic year. As the questionnaires were completed monthly, recall bias was reduced. Moreover, we presented data based on four different injury definitions described in the literature and therefore present a clear overview of the incidence of ankle injuries within this population. ${ }^{1416}$ Nevertheless, a limitation that needs to be addressed is that we only included a follow-up of one academic year. As the incidence and the risk of an ankle injury might change throughout academic training, a follow-up period over all academic years might give a more representative overview of injuries. Another limitation is that in three out of four injury definitions, we used student reported outcomes. Most dance students lack medical expertise and, as such, diagnostic information may be misclassified. Additionally, symptoms or time-loss may be under-reported or exaggerated by the participants.

\section{CONCLUSION}

This study is the first study that provides an overview of ankle injuries among contemporary dance students and identifies ankle injury risk factors. Almost $20 \%$ of firstyear dance students reported an ankle injury during one academic year, with more than $80 \%$ of these injuries leading to dance time loss. Males and students of the BDE seem to be at a lower risk of ankle injuries. Further research conducting studies with larger sample sizes, a more heterogeneous population (eg, different dance styles) and longer follow-up periods is deemed necessary to evaluate this type of injury, especially considering that ankle injuries are the most common injuries among (pre) professional dancers.

\section{Twitter Rogier M van Rijn @RogierRijn}

Contributors All authors have substantially contributed to conception and design, acquisition of data or analysis and interpretation of data, drafting the article or critical revision of the content, and final approval of the version to be published.

Funding This work was supported by the Taskforce for Applied Research SIA (regieorgaan SIA) (grant numbers 2015-02-73P and SPR.VG01.007).

Competing interests None declared.

Patient and public involvement Patients and/or the public were not involved in the design, or conduct, or reporting, or dissemination plans of this research.

Patient consent for publication Not required.

Ethics approval Ethical approval was given by the Medical Ethics Committee of the Erasmus MC University Medical Center Rotterdam, the Netherlands (MEC2019-0163).

Provenance and peer review Not commissioned; externally peer reviewed. Data availability statement Data are available on reasonable request.

Open access This is an open access article distributed in accordance with the Creative Commons Attribution Non Commercial (CC BY-NC 4.0) license, which permits others to distribute, remix, adapt, build upon this work non-commercially, and license their derivative works on different terms, provided the original work is properly cited, appropriate credit is given, any changes made indicated, and the use is non-commercial. See: http://creativecommons.org/licenses/by-nc/4.0/.

ORCID iD

Rogier M van Rijn http://orcid.org/0000-0002-5174-8321

\section{REFERENCES}

1 Kenny SJ, Whittaker JL, Emery CA. Risk factors for musculoskeletal injury in preprofessional dancers: a systematic review. $\mathrm{Br} J$ Sports Med 2016;50:997-1003.

2 van Winden DPAM, Van Rijn RM, Richardson A, et al. Detailed injury epidemiology in contemporary dance: a 1-year prospective study of 134 students. BMJ Open Sport Exerc Med 2019;5:e000453.

3 Ekegren CL, Quested R, Brodrick A. Injuries in pre-professional ballet dancers: incidence, characteristics and consequences. J Sci Med Sport 2014;17:271-5.

4 Ramkumar PN, Farber J, Arnouk J, et al. Injuries in a professional ballet dance company: a 10-year retrospective study. J Dance Med Sci 2016;20:30-7.

5 Smith PJ, Gerrie BJ, Varner KE, et al. Incidence and prevalence of musculoskeletal injury in ballet: a systematic review. Orthop J Sports Med 2015;3:2325967115592621.

6 Vassallo AJ, Hiller C, Stamatakis E, et al. Epidemiology of DanceRelated injuries presenting to emergency departments in the United States, 2000-2013. Med Probl Perform Art 2017;32:170-5.

7 Luke AC, Kinney SA, D'Hemecourt PA, et al. Determinants of injuries in young dancers. Med Probl Perform Art 2002;17:105-12.

8 Zaletel P, Sekulić D, Zenić N, et al. The association between bodybuilt and injury occurrence in pre-professional ballet dancers Separated analysis for the injured body-locations. Int J Occup Med Environ Health 2017;30:151-9.

9 Simon J, Hall E, Docherty C. Prevalence of chronic ankle instability and associated symptoms in University dance majors: an exploratory study. J Dance Med Sci 2014;18:178-84.

10 Smith TO, de Medici A, Oduoza U, et al. National survey to evaluate musuloskeletal health in retired professional ballet dancers in the United Kingdom. Phys Ther Sport 2017;23:82-5. 
11 Campoy FAS, Coelho LRdeO, Bastos FN, et al. Investigation of risk factors and characteristics of dance injuries. Clin J Sport Med 2011;21:493-8.

12 van Seters C, van Rijn RM, van Middelkoop M, et al. Risk factors for lower-extremity injuries among contemporary dance students. Clin J Sport Med 2020;30:60-6.

13 van Mechelen W, Hlobil H, Kemper HC. Incidence, severity, aetiology and prevention of sports injuries. A review of concepts. Sports Med 1992;14:82-99.

14 Kenny SJ, Palacios-Derflingher L, Whittaker JL, et al. The influence of injury definition on injury burden in Preprofessional ballet and contemporary dancers. J Orthop Sports Phys Ther 2018;48:185-93.

15 Stracciolini A, Yin AX, Sugimoto D. Etiology and body area of injuries in young female dancers presenting to sports medicine clinic: a comparison by age group. Phys Sportsmed 2015;43:342-7.

16 Clarsen B, Myklebust G, Bahr R. Development and validation of a new method for the registration of overuse injuries in sports injury epidemiology: the Oslo sports trauma research centre (OSTRC) overuse injury questionnaire. Br J Sports Med 2013;47:495-502.

17 Liederbach M, Hagins M, Gamboa JM, et al. Assessing and reporting dancer capacities, risk factors, and injuries: recommendations from the IADMS standard measures consensus initiative. J Dance Med Sci 2012;16:139-53.

18 Langarika-Rocafort A, Emparanza Jl, Aramendi JF, et al. Intra-rater reliability and agreement of various methods of measurement to assess dorsiflexion in the weight bearing Dorsiflexion Lunge test (WBLT) among female athletes. Phys Ther Sport 2017;23:37-44.

19 Stubbe JH, Richardson A, van Rijn RM. Prospective cohort study on injuries and health problems among Circus arts students. BMJ Open Sport Exerc Med 2018;4:e000327.

20 Karreman DE, Keizer-Hulsebosch SC, Stubbe JH. Performing artist and athlete health monitor: user experience, content and conditions for use of an online dance-health surveillance system in a professional ballet company. BMJ Open Sport Exerc Med 2019;5:e000566.

21 Fuller CW, Ekstrand J, Junge A, et al. Consensus statement on injury definitions and data collection procedures in studies of football (soccer) injuries. Clin J Sport Med 2006;16:97-106.

22 Knowles SB, Marshall SW, Guskiewicz KM. Issues in estimating risks and rates in sports injury research. J Athl Train 2006;41:207-15.
23 Pavlou M, Ambler G, Seaman S, et al. Review and evaluation of penalised regression methods for risk prediction in low-dimensional data with few events. Stat Med 2016;35:1159-77.

24 Pavlou M, Ambler G, Seaman SR, et al. How to develop a more accurate risk prediction model when there are few events. BMJ 2015;351:h3868.

25 Baker J, Scott D, Watkins K, et al. Self-reported and reported injury patterns in contemporary dance students. Med Probl Perform Art 2010;25:10-15.

26 Gamboa JM, Roberts LA, Maring J, et al. Injury patterns in elite preprofessional ballet dancers and the utility of screening programs to identify risk characteristics. J Orthop Sports Phys Ther 2008:38:126-36.

27 Smith TO, Davies L, de Medici A, et al. Prevalence and profile of musculoskeletal injuries in ballet dancers: a systematic review and meta-analysis. Phys Ther Sport 2016;19:50-6.

28 Vassallo AJ, Hiller C, Stamatakis E, et al. Epidemiology of DanceRelated injuries presenting to emergency departments in the United States, 2000-2013. Med Probl Perform Art 2017;32:170-5.

29 Weigert BJ. Does prior training affect risk of injury in University dance programs? Med Probl Perform Art 2005;20:115-8.

30 Caine D, Bergeron G, Goodwin BJ, et al. A survey of injuries affecting Pre-Professional ballet dancers. J Dance Med Sci 2016;20:115-26.

31 Vassallo AJ, Pappas E, Stamatakis E, et al. Injury fear, stigma, and reporting in professional dancers. Saf Health Work 2019:10:260-4.

32 Gabbe BJ, Finch CF, Wajswelner H, et al. Predictors of lower extremity injuries at the community level of Australian football. Clin $J$ Sport Med 2004:14:56-63.

33 Martin RL, Davenport TE, Paulseth S, et al. Ankle stability and movement coordination impairments: ankle ligament sprains. $J$ Orthop Sports Phys Ther 2013;43:A1-40.

34 Bronner S, Bauer NG. Risk factors for musculoskeletal injury in elite pre-professional modern dancers: a prospective cohort prognostic study. Phys Ther Sport 2018;31:42-51.

35 van Rijn RM, Stubbe JH. Generalized joint hypermobility and injuries: a prospective cohort study of 185 Pre-Professional contemporary dancers. J Clin Med 2021:10:1007. 